\title{
Electronic Payments Profitability Extent Model
}

\author{
Rudolf Vohnout", Zora Říhová*†, Iva Dostálková*
}

\begin{abstract}
Cashless payments are recent phenomena, which even increased with the introduction of contactless means like NFC, PayPass or payWave. Such new methods speed-up the entire payment process and in comparison to cash transactions are much simpler and faster. But on the other hand the key question for merchant is if it is worth to have such device, which accept these new payment means or not to have the terminal at all. What is the amount of cash flow, which delimits the cash holdings to be still profitable? This paper tries to give answers to such question by presenting general profitability model, which will address defining the cash threshold amount. The aim is to show that cash holdings could be profitable up to certain amount, but after the threshold is met, cashless payment methods are fairly superior despite their additional costs.
\end{abstract}

Keywords: Cashless, Contactless, Card, Fee, Merchant, Payment, Transaction.

\section{Introduction}

As new payment systems have been introduced, researchers have critically examined their costs from both a private and social perspective. Scholars have studied why individuals and firms use or accept various payment instruments. Some have also considered whether economic welfare would be improved if certain payment instruments displaced others, such as if electronic instruments displaced paper-based instruments. This should make payments system more transparent to whole society and let users control their budgets better, prevent illegal payments and taxes leakages.

Society benefits of using the electronic money are obvious. The tracking a logging all transactions is a very good procedure how to minimize illegality on both sides. On the other hand, every good thing could be abused and cashless payments tries to minimize potential security risks and makes the whole system more reliable. Using cash also has its own advantages. However, it will be more and more impractical in future. Regulators claimed that electronic payment systems charge "unjustifiably high" fees to merchants while the banks issuing electronic payment instruments provide consumers with below-cost services and loyalty rewards and this occasionally prevent cashless society boom. This is however the fact of the past, because with increase of cashless transaction popularity and introduction of new

\footnotetext{
*Institute of Applied Informatics, Faculty of Science, University of South Bohemia in Ceske Budejovice,

Branisovska 1760, 37005 Ceske Budejovice, Czech Republic

$\triangle$ rudolf.vohnout@prf.jcu.cz

${ }^{\dagger}$ Department of Systems Analysis, Faculty of Informatics and Statistics, University of Economics, Prague,

W. Churchill Sq. 4, 13067 Prague 3, Czech Republic

$\triangle$ zora.rihova@vse.cz
} 
cashless payments means society pushed national governments to support expansion of this way trade by regulating the interchange fees to minimum.

A deeper understanding of the economics of payment instruments could have important implications for policy. Retailer cost studies suggesting that payment cards are very costly are misleading when used to argue that payment cards are costly for the economy as a whole. By not charging consumers the full marginal cost imposed by their card use, the regulators assert that payment card systems encourage consumers to overuse payment cards, which they can afford to do profitably because merchants shoulder the cost. The empirical applications should illustrate how cost-benefit analysis can provide policy makers with insights on how moves toward a cashless society affect net economic welfare. In recent years this has been also supported by extensive development of new cashless instruments like contactless cards (PayPass, payWave), NFC technology or Mobile (e.g. PayPal or inCard) payments or support for QR codes in many smart banking applications. Such payments are so-called e-payments in the European Union territory. As could be seen in the following chapters inevitable shift toward a cashless society is beneficial, providing certain groups with clear benefits while not costing more to process in aggregate than traditional paper transactions.

\section{Motivation}

This paper wants to show that inevitable shift toward a cashless society is beneficial, providing certain groups with clear benefits while not costing more to process in aggregate than traditional paper transactions. In brief main objective is to prepare all necessary steps for empirical examination of the move toward a cashless society using benefits as well as costs. The outcomes from this paper could be beneficial for people who are already part of cashless society but primary for those who are still afraid of electronic transactions and prefer cashrelated payments.

Of course, then main fear today is the "big-brother" that takes watch over the cashless transactions and there is always evidence ready to be used in case of (authorized) need. This does not influence only the consumer but also the merchant. In several countries, new phenomena called "Electronic Record of Sales (ERS)" (Pražská, Otáhalíková \& Dostál, 2016) had been implemented and enshrined in particular legal act (e.g. Croatia since 2013, Slovakia since 2008 and Czech Republic will adopt it in 2017).

\subsection{Basic definitions}

- Cashless society: society that does not use cash. A theoretical society in which consumers purchase all goods and services by card or any other electronic transaction means (including electronic funds bank transfer), without the use of cash. Cashless society is using all means of cashless payments available.

- Merchant acquirer: An organization licensed as a member of Visa / MasterCard as an affiliated bank or bank/processor alliance that is in the business of processing payment instrument transactions for businesses (acceptors) and is always acquiring new merchants.

- Interchange fees: fees paid by merchant-acquiring banks to cashless mean holderissuing banks are in place to cover the cost to convert a charge on a holder's electronic payment instrument to a cash deposit at the merchant business checking account, including cost factors like billing services, ATM (cash machine) transaction etc. An interchange rate payable when such instrument is used that is high enough for the 
issuing bank to make a profit provides financial incentives for banks to market, issue, and accept credit risk of holders.

\subsection{Research design and research questions}

Research design contains mainly quantitative data collections. Qualitative data include consumer's and merchants' non-monetary benefits. Quantitative data collections involve income, fees, costs etc. Following explanations will give us better understanding.

In order to present the best possible answers to the particular questions appropriate research strategy has to be chosen. The relations in schematic model above can give us overall scope of the interactions. They have their own patters "how that works in the reality" including affecting attributes of the consumers and merchants. However, the model leads us to express explanations to the research questions. The most suitable research strategy for this particular problem seems to be case study, which can present rich understanding of the context of the research, as well it is a perfect tool to answer to two basic questions: what? and how?

- Is the nowadays market prepared for the huge increment of cashless payments and their means?

In the beginning data collection from official statistical resources, like annual reports should be taken. Example of data to look for will be amount of transactions and their nowadays payments system loads. Next step would be explanatory research from the collected data. Outcome of the previous steps will be theoretical evaluation of the market readiness for electronic payment increment.

- More specifically, are the merchants prepared for the huge increment of cashless payments?

Partial exploratory research strategy to try to empirically answer for this question can be used. primary data collecting methods will be used which should complement secondary data collections from the previous research question. Successive data analyses will outcome coherent relation among trade and merchants perspectives of the card payments increment. It is worth to point out that the merchants are usually pushed by the customers as well ("you do not accept card? I will not come over again...”).

- Will people use cashless payments more if we prove, show and emphasize them that benefits are higher than costs?

Before to begin to answer this question it is important to consider that we have to let know the results to the society. Firstly, it should be found out what electronic payment instrument issuers do for the electronic mean's usage benefits emphasizing, secondly to check out how much is this policy effective and thirdly eventually use reverse engineering to find out what did they wrong. This related hand in hand with new, more efficient methodical expression for convey of the cashless-related usage within society.

- Are there any changes needed in the current payment system?

Basis on the previous analysis and question answers it could be eventually suggested some changes and additions to the current cashless payment system. These suggestions will strictly follow gained data from the various resources which were mention above. Of course the suggestions will be considered as recommendations for the application to whole society. 
- Can we make universal research model for incoming ways of payments?

This is a very theoretical question and universal model construction desperately depends on chosen variables and universal usage of applied terms and their mutual relations and interactions. The basic that could be said at this time is that there will be always advantages (benefits) and disadvantages (costs) which will influence the final decision of the parties.

\subsection{Research objectives}

From the research questions the following research objectives can be concluded:

- To prove that cash transactions will probably continue to decline in the society.

- To show how reward and bonus system motivates and stimulates use of cashless transaction means.

- To find out the extent that is beneficial for merchants to accept cashless payments instead of possession of cash.

\subsection{Conceptual framework and hypotheses}

The conceptual framework for the propositional statements for this particular research problem will be presented. Decision-making of merchants and consumers to accept cashless payments is influenced by costs and benefits. The concepts comprehend items which compose costs and benefits and they are later variable measurable. The concepts are:

- Cashless transactions rewards.

- Cash payments and handling costs.

- Cashless transaction proportional fee.

- Adaptive costs.

- Provision of the cashless service costs.

Hypothesis 1: Human is lazy in his natural matter and basic micro-economics law says that human maximizes his utility. After presenting advantages and benefits (e.g. rewards or time savings) of the cashless payment system he will use. Similarly, merchants will use that cashless payment type which will be reliable and guarantee him lower costs.

Hypothesis 2: Cash-related payments will have higher costs than electronic-related and from available indicators it is predictable that the cashless society is on its way and it will grow.

Hypothesis 3: From historical evolution it can be deduced that new ways of electronic payments (and payments itself) will be make up and interchange fees under the governments regulations will continue to decrease (European Commission, 2015) and ideally will be wiped completely (European Commission, 2016a).

To better understand the conceptual framework it is always good move to present a general scheme (to clarify environment) under which the model proposal later on will be based on, or fit into. 


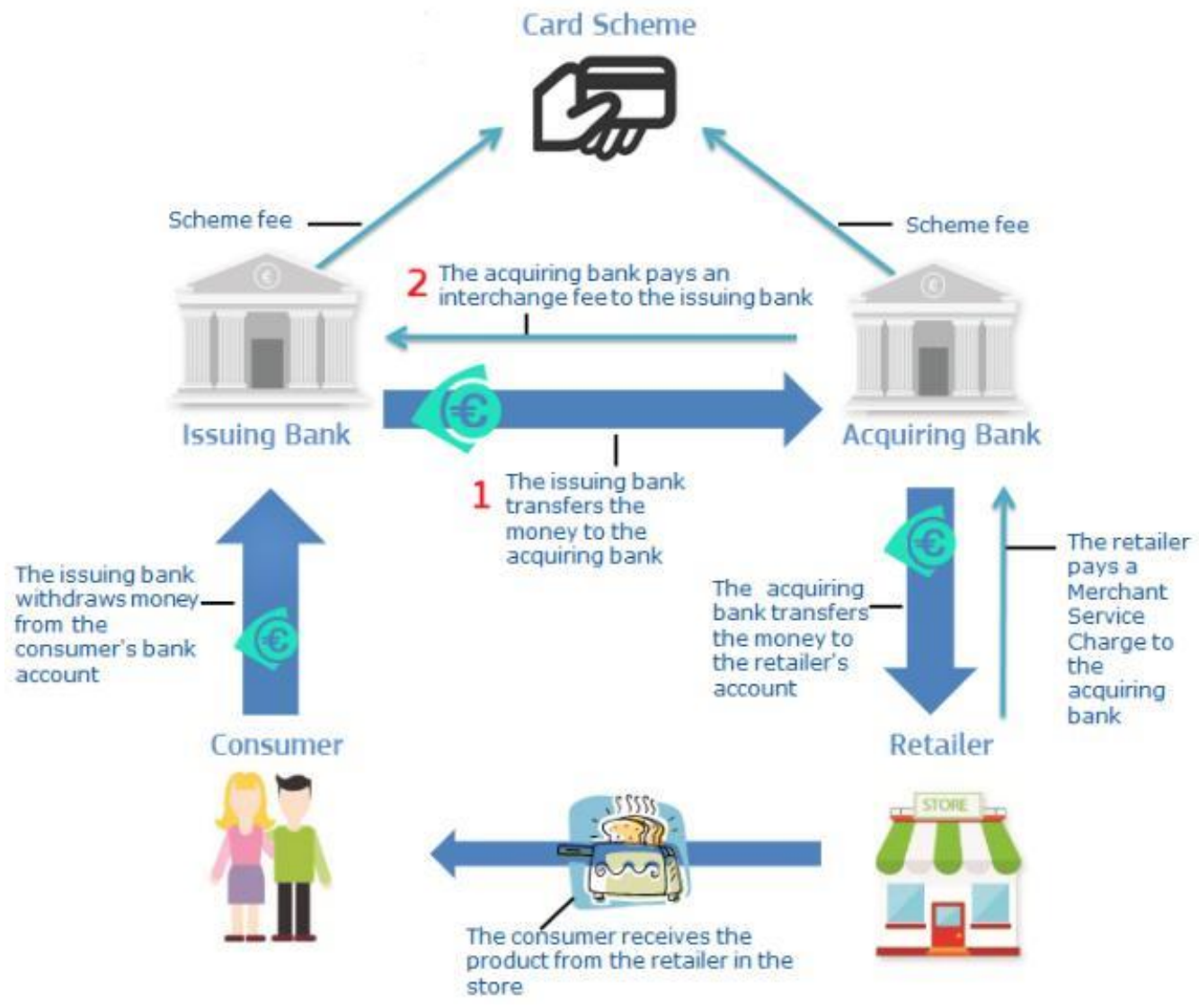

Fig. 1. Conceptual Framework Scheme Source:(Wang, 2006).

\section{Short review of related literature}

There are plenty of economic literature titles concerning electronic payments, however not so many which focus on consumer/retailer benefit analysis. There are also few scientific papers which were published electronically. Some of them are listed in the references section.

One of the most essential works so far is the Garcia-Swartz, Hahn and Layne-Farrar (2006) paper. It mentions important aspects like costs related to each transaction type, which are analysed in detail. This work gathers information from official resources like VISA USA, or MasterCard year annual reports. Benefits to users are clearly explained and proved by statistical data. Two case studies were present with both social costs and social benefits. The first one focuses on the consumers and their costs, how they change in relation to the electronic payment amount. As it could be obvious with higher amounts the user-related costs decrease. The second case study focuses on the seller cost and problem connected with bank institution's fees. It is also mentioned that not all benefits to users were show because it is very difficult to find all of them. Finally, and most importantly, the relative merits of different payment methods change significantly when all parties are counted and benefits are included. What is cheap for merchants is relatively expensive for other parties to a transaction. Certain parties, especially consumers, receive considerable benefits from payment cards, which tip their net private costs in favour of that method of payment. The paper found that when all key parties to a transaction are considered and benefits are added, cash and checks are not as desirable as many earlier studies suggest. The fact that the shift away from cash and checks is probably economically beneficial does not imply that all parties have benefited. However, in 
general, the shift toward a cashless society appears to improve economic welfare. The paper misses some graphical output results for that amount of tables and it is hardly visible if there is some primary data collection and where it was obtained Garcia-Swartz, Hahn and LayneFarrar (2004).

Ching and Hayashi (2006) paper proves that people decision about usage of credit (debit) card is highly influenced by issuers reward programs. Consumers with rewards use a credit card more often than those without rewards and also consumers who receive rewards only from credit cards tend to use it more exclusively, while consumers who receive rewards from both credit and debit cards tend to distribute their transactions more 'equally' between both types of cards. Finally, this work shows that reward card transactions replace not only paper-based transactions but also non-reward card transactions. Most studies in the literature (Rochet and Tirole 2002, Hayashi 2006) rely on restrictive assumptions: consumers have a fixed demand for goods (irrelevant to their payment choices); merchants engage in a special form of imperfect competition (e.g., Hotelling) and there is no entry/exit of card issuers. Although that framework is handy to consider merchants' business stealing motive for accepting cards, it has ignored critical issues beyond those assumptions. Particularly, the pricing of payment does affect consumers' demand for goods; the entry and exit of card issuers are endogenous; and most important, interchange fees play a key role in network competition for attracting issuers.

It stands in contrast to much of the literature regarding payment devices, with the notable exceptions of Farrell (2006) or Rochet and Tirole (2006). In the more standard approach to modelling payment device markets in the two-sided market literature, as in Rochet and Tirole (2003) or Evans and Schmalensee (2005), consumers and merchants derive benefits from their use of a particular payment device. Under conditions that lead to two-sided markets interchange fees then play a role in balancing the demands on the two sides of the markets for some objective, either to maximize transaction volume (welfare) or to maximize the profits of the provider of the payment device. This modelling technique has the merchants and consumers in essentially symmetric positions, both having direct demands for the payment device. In this now standard approach, the consumer's benefit from the use of the card is referred to as the convenience benefit from the payment device. Although these models are partial equilibrium models (as is the one presented) they largely overlook the monetary nature of the payment device. These models are only partially applicable to payment devices, and only so when the payment device, such as a payment card, offers some direct benefit (utility) to the consumer in addition to the ability to make monetary transfers.

Even if merchants compete and consumers are fully informed as to whether merchants accept cards, the profit and welfare maximizing fee coincide for a non-trivial set of cases. In contrast, other studies try to identify potential anti-competitive effects of the collective determination of interchange fees, but most of them lack a formal treatment (Katz 2001).

The consumer payment study by Dove Consulting (2005) showed that the consumers' payment mix varies by the type of store. Hayashi and Klee (2003) also found that a consumer's payment choice depends on the transaction characteristics, such as average transaction value and physical characteristics at the points of purchase, although larger merchants in a given industry may pay lower merchant fees than their smaller counterparts.

As an absolute essential and motivation paper should be considered Wolman (2013) who did a social experiment all over the world, where he had decided to avoid cash payments for entire year and will observe counterpart reactions. This way he had proved that in modern 
society cash penalizes poor much more than anyone. And mobile and other modern cashless technologies should change that.

\section{$4 \quad$ Research approach and methods}

Approach requires examining the incremental transaction and posing the following question. What are the costs and benefits of electronic transactions for each one of the parties involved? In order to properly address this question, three issues must be considered. First, both parties must be taken into account (merchants and consumers). Payment instruments that are beneficial, for one of the actors may not be for society as a whole. Second, it is necessary to carefully distinguish true resource costs from transfer payments. Third, both cost and benefits for all participants need to be count. To test the hypothesis, it has been mentioned in the beginning that research approach will be deductive which means that basis on theory and hypotheses design research strategy has to be established to actually test the hypotheses.

The approach will be strictly monetary-related orientation only. By overlooking the monetary nature of payment devices, it will lead to misunderstand the basic asymmetry between the economic roles of the consumer and the merchant. Primary reason for this step is the nature of payment devices which is arguably their primary purpose. Second reason is that many convenience benefits of payment devices (e.g. protection from theft or time saving), are closely related with the income and spending of the consumer, and are therefore better captured by this model through the variable cost of use of the payment device. By first investigating the adoption pattern of a monetary payment device it can be better understand the circumstances under which sellers of payment devices will choose to employ a strategy of tying a direct benefit (not related to the income of the consumer) to the use of the device, and determining on which side of the market those benefits might be offered.

This work itself will use methods of classification and relation analysis. System model (proposal) will be based on proposal analysis which will use theoretical and empirical verification from secondary data resources.

\section{$5 \quad$ Research model}

From the theoretical basics of the cashless payments it is possible to prepare research model, which can be understand in two perspectives. The first one is from the customer's point of view and the second one is from the merchant's point of view. Following model doesn't only represent their mutual interactions, but moreover factors which influence their decision in the payment process. Initial environment characteristics have to be set up: To simplify model below it must be expected that identical merchants sell a homogenous good on the market. Also all consumers have access to cash and most of them also own any of cashless instruments available on the market.

- Cashless transactions rewards and discounts (related to Consumer only): Customers receive rewards for cashless transactions such as frequent flier points, gift certificates, or cash back as an incentive to use the electronic payment instrument. As a measurement variable Cashless transactions rewards height will be used.

- Times savings, convenience and lower risks. Even though some of the items could be proved by numbers, convenience is difficult to measure (lazy human being nature). Despite the importance of these factors, they will not be considered in the model proposed. 
- Cash payment and handling costs (related to Consumer and Merchant): Cash payments and usage incur costs such as storage and safekeeping. Due to no-surcharge rules imposed by cashless networks (such as theft); those for merchants include handling cash transactions (such as costs of labour, armed car, and bank fees, evokes costs for safe depository, misuse cashless payments is much lower than cash etc.). Another significant aspect is human factor elimination (e.g. costs for bad counting, earnings errors etc.). Generally, transactional costs with cash for consumers include costs of obtaining cash (such as ATM fees and time to go to the bank) and risks associated with cash. As a variable Cash payment and handling costs amount will be used.

- Cashless transaction proportional fee (related to Consumer and Merchant): This is a fee which is charged for every cashless payment. Proportional means its true amount bases on the payment amount. On consumer's side this is usually zero. These costs are better known as interchange fees ${ }^{1}$. Provider of the card charges the bank (and this bank charges the end-users of the transaction - Consumer \& Merchant). As a measurement variable Cashless transaction proportional fee amount will be used.

- Adaptive costs (related to Merchant): These costs include acquire of fixed cost of renting cashless-processing equipment (e.g. payment terminal), fixed cost of maintaining banking account balance or credit score, secured internet connection to the bank, insurance etc. Adaptive because they are related to adapting to the new technology (system). As a measurement variable adaptive costs amount will be used.

- Provide of the card (POS) service costs (related to Consumer and Merchant): This costs are related with cashless service to the both sides of the contract. These are costs which end-users (Consumer \& Merchant) have to pay to the bank which issued the payment instrument. On consumer's side they could be zero. As a measurement variable Provide of the card service costs amount will be used.

\footnotetext{
${ }^{1}$ The interchange fees in the US are among the highest in the world. In the UK, the Office of Fair Trading announced in 2005 its intention to regulate down MasterCard's credit card interchange fees as well as investigate Visa's. In the European Union, the European Commission pushed the Visa International to agree to reduce its cross-border interchange fees on credit and debit transactions in 2002. In Australia, the Reserve Bank of Australia mandated a sizeable reduction of credit-card interchange fees in 2003 and is considering doing the same for debit transactions. In 2014 MasterCard conclusively lost its battle against EU (Chee, 2014).
} 


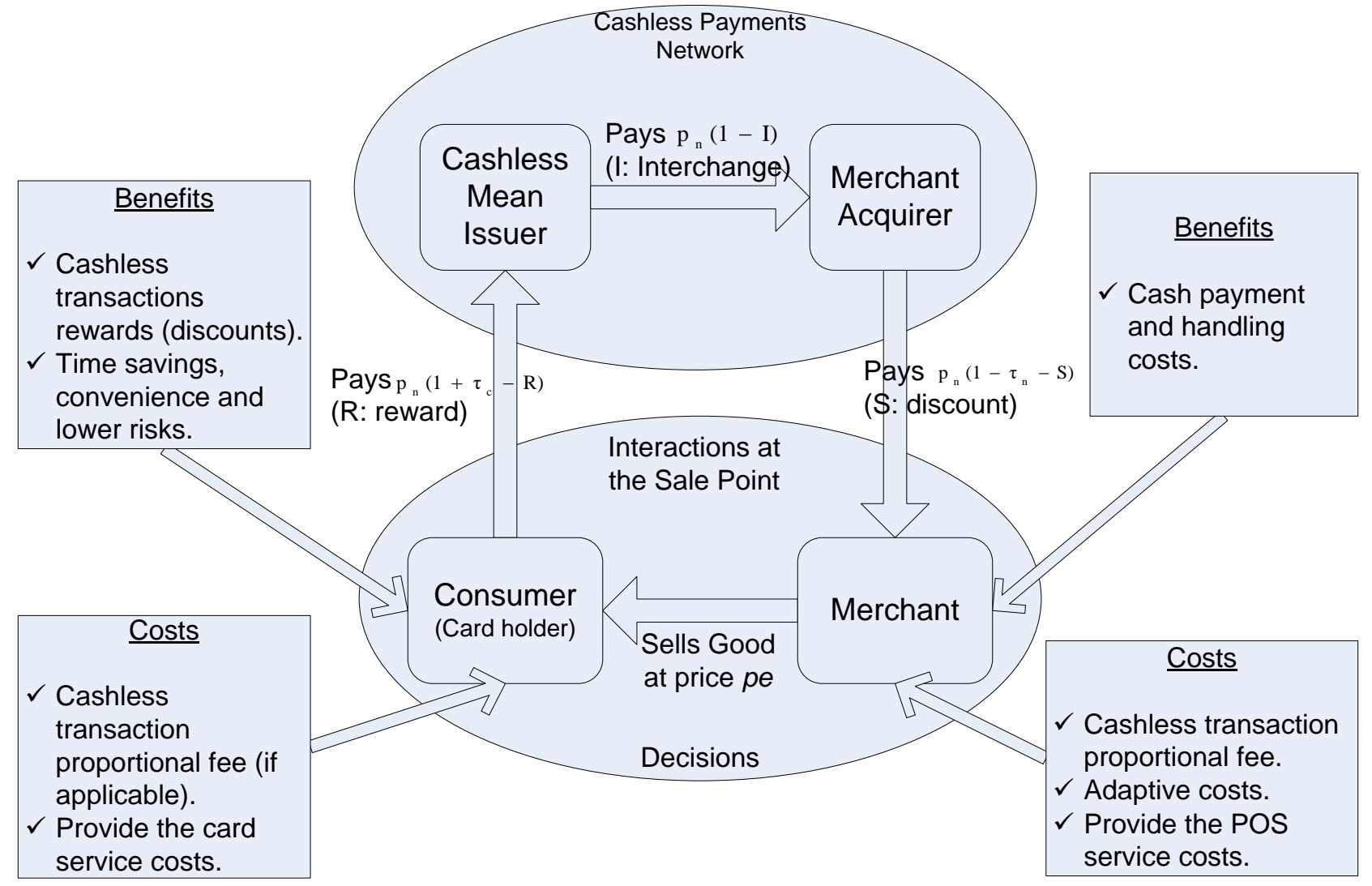

Fig. 2. Research problem graphical model. Source: Authors.

For the basic understanding of the model benefits and costs relations to the concerned parties have to be determined. Let's say that $C$ represents individual costs and $B$ represents individual benefits. Then it has to hold true that:

$$
\sum_{n}^{1} C<\sum_{m}^{1} B
$$

In other words, overall benefits must be higher that overall costs. This holds true for both participating sides. A cashless transaction brings transactional benefits to both - the users and the merchants who accept those payment instruments. One of the transactional benefits of cashless payments is reducing transactional costs associated with cash transactions for both consumers and merchants. When consumers pay with cash, the consumers incur some transactional costs besides the price of goods or services they purchase and the merchants also incur some transactional costs in addition to the costs of selling goods or services.

Rational consumers (merchants) that always use (accept) the lowest-cost payment instruments. The merchant accepts whatever cashless payment instrument if the merchant fee is lower than the merchant transactional costs with cash. The merchant may accept electronic payment instruments even when the merchant fee exceeds the merchant transactional costs with cash, if raising the price increases the merchant's profit.

To simplify the model cash-related costs as benefits of cashless-related payments will be used. As mention and explained in the previous chapter, only monetary-related aspects will be considered. To use appropriate variable(s) in measurement section it should get very good scope and understanding of the whole model. Non-monetary cash-related benefits and costs 
like anonymity, human factor elimination, risks etc. are highly related to monetary aspects and furthermore they are hardly measurable in practice.

The model assumes that there exists only one cashless network, which sets both merchant fees and the cardholder fee. The network sets a unique merchant fee in a given industry and a universal cardholder fee. Merchants are assumed to set the same price for both, cash and cashless users. The network imposes the no-surcharge rule, which prohibits merchants from charging a higher price to cashless payment instruments users. Consumers are either cardholders or non-cardholders. Non-electronic payment users need to pay with cash all the time (rare nowadays in modern society - but not in developing, rural countries). On the other hand, cashless-friendly users can choose their payment method - either go cash or cashless way. Consumers observe all the decisions the merchants made (card acceptance and new price) before they determine their payment methods, the merchants from which they make purchases.

In contrast to the consumer, the merchant's decision to adopt the innovation of the cashless payment involves both the merchant's and consumers' variable and fixed cost of adopting the cashless payment. This asymmetry in the consumer's and merchant's decision problem is a key feature of the monetary approach to modelling electronic payment adoption. In the electronic payments network cloud the acquiring market is competitive and each acquirer receives a merchant discount rate $S$ from merchants and pays an interchange rate $I$ to card issuers. For simplicity in our analysis, merchant discount as interchange fee to the issuers have to be normalized, i.e. $S=I$.

\section{Measurement issues}

Cash transactions rewards height: Let signify it $R$. In many cases the rewards are in the form of bonus points on the bonus account. Those bonus points can be later spent in various ways. There are few essential methods how to calculate the reward bonus point amount, however for our case the most suitable is the following one:

$$
R=p_{n} * f_{b}-\tau_{c}
$$

Where: $\quad p_{n} \ldots . .$. Sold and charged price of the $n$-th good.

$f_{b} \ldots \ldots$...Bank rewarding percentage $(f b \in<0 ; 1>$ where 1 means $100 \%)$.

$\tau_{c} \ldots . . . .$. Fee for the cashless transaction.

Cash payment and handling costs amount: Let signify it $\tau_{m}$. These costs are charged always when merchant accepts cash (which is almost always with only few exceptions). They are always (with minor exceptions) present on the consumer side if he operates with cash. The basic way how to illustrate is on an example calculation of the final charged price:

$$
p_{n}=\frac{p_{0}}{1-\tau_{m}}
$$

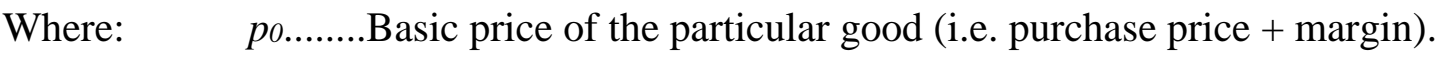

$\tau_{m}$.......Cash payment handling costs $\left(\tau_{m} \in<0 ; 1>\right.$ where 1 means $\left.100 \%\right)$ 
Cashless transaction proportional fee amount: Let signify it $\tau_{n}$. Because in most cases there are no cashless transaction proportional fees charged to consumers (all costs are on the merchant's shoulders) it must be excluded them from the following figure to simplify it:

$$
\tau_{n}=p_{n} *\left(f_{c}+\tau_{I}\right)
$$

Where: $\quad p_{n} \ldots . .$. Sold and charged price of the $n$-th good.

$f_{c} \ldots . .$. Percentage charged by bank $(f c \in<0 ; 1>$ where 1 means $100 \%)$.

$\tau_{I} \ldots \ldots . .$. Interchange fee rate for the electronic transaction $\left(\tau_{I} \in<0 ; 1>\right)$

Adaptive costs amount: Let signify it $k_{m}$. Costs which are fixed for per-period (one month, one year etc.). Those costs are independent on the cashless transactions, their count or charged amount. These costs are various from bank to bank and they depend on several factors, therefore it is very hard to measure it generally. For the card adoption it must be truth that:

$$
\left(p_{n}-\tau_{n}\right)>k_{m}
$$

Provide of the cashless service costs amount: Let signify it $S$. They are strongly related to the costs which banks have with the merchant's (consumer's) electronic payment service provision. They are based on the charged amounts and frequency of the electronic transactions and time for which merchants (consumers) use the cashless payment service. In a competitive electronic payment service market where it is not feasible to assess an interchange fee, we have:

$$
S=f_{c}
$$

However we live in a world with interchange fees so:

$$
\begin{gathered}
S=p_{n} * h_{b} \quad \text { where } \\
h_{b}=p_{a} * p_{f} * p_{t}
\end{gathered}
$$

Where: $\quad p_{n} \ldots . .$. Sold and charged price of the $n$-th good.

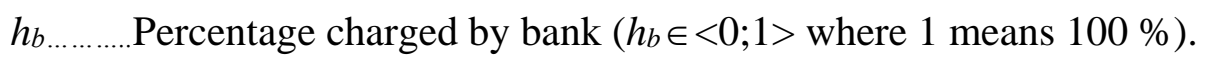

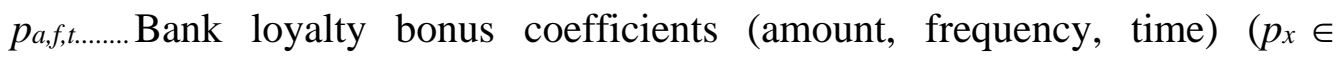
$<0,01 ; 0,2\rangle)$. Lower $=$ better.

All the above presented variables contain characteristics of ratio scale. However sometimes variable of $R$ can also has properties of interval scale because in few approaches rewards are considered as negative card transaction proportional fees.

\section{Data collection and sampling}

In case that research problem fit in macroeconomics sphere it is very difficult to get primary data collection. Even though there will be opportunity to collect some primary data they will be irrelevant because only small sample of society will be involved. Therefore, the data will be inaccurate in macroeconomics point of view and we cannot produce any trustworthy results.

Cashless transactions rewards height: The rewards are offered by banks to their customers for electronic means transactions. These rewards are often counted as bonus points, and for particular amount of the bonus points you are able to choose some reward. Principle is simple - the more you use e.g. the card, i.e. the much amount that you pay more bonus points you 
get. Ways how to obtain data about rewards offered by banks, as bonus point calculations, sort of offered rewards etc. are:

- From the secondary online resources (i.e. web sites of the banks).

- From statistical reports, like annual reports etc.

For the measurement issues financial related materials like economy papers, scientific research papers and reports will be used. Very good are also outcomes from financial books and macro economical on-line resources.

Cash payment and handling costs amount: Because these costs relate to risks, theft etc., i.e. non-monetary aspects, exact method is not easy to define. Significant criteria are consumer's income and merchant's sales. Certain part of the budget contains cash. For larger cash amount more investments for cash storing, its securing etc. are necessary. For exact data of the cash handling costs it should be looked for in:

- Scientific financial-oriented works.

- Bank electronic payments research papers, related to merchants (e.g. when acquiring merchants for the electronic payment system).

- Retail stores for the prices (e.g. for safe-boxes).

Cashless transaction proportional fees and cashless service providing costs amounts: Sensitive information which are set in mutual agreements and they are mostly confidential. Exact values are not accessible to public (of course exceptions can exist). Approximate known interval in which the percentage values flows is between $0,5 \%$ and $2 \%$ of the transaction amount. Sometimes could happen that card issuers like MasterCard or VISA publish their interchange fees. Resources where these values can be obtained from are:

- Bank's internal materials (merchant's acquirer and card holder's issue bank).

- Mutual agreements between merchant and his acquirer.

- VISA and MasterCard internal documents, reports, annuals

Adaptive costs amount: They are related on one side to the bank (account maintaining costs), on the other side to merchants (necessary essential costs for partial change to the cashless payments, e.g. safe-box elimination).

\section{Model verification proposal}

By reason of many data collections from secondary data resource it is obvious that some quantitative statistic technique should be applied. This makes whole research proposal more transparent and understandable to the audience.

Adaptive costs, cash payment and handling costs amounts: Merchants decide not only their cashless instruments acceptance strategy but also their prices. So in the begging when merchants think about entering the business, they have to decide about the way of payments. So they will make analysis of the available ways of payments and they will compare various multi-criteria decisions which payment system they will accept. For this decision-making problem the best suitable approach how to analyse costs vs. benefits is multi-criteria decisionmaking methods (MCDM). They enable a complex, integrated and logical framework that allows for interaction and interdependence among factors, and they enable consideration of different, more or less conflicting dimensions.

Cashless transaction proportional fees, card service providing costs amounts and electronic transactions rewards height: The existing studies on electronic payment market (Weiner, 
Stuart \& Wright, 2006) typically assume imperfect competition among merchants, e.g. hoteling competition. Those models allow the merchants to behave strategically and consider the business stealing motive for adopting any electronic payment system, but cannot easily keep track of market dynamics. Hayshi model (Hayshi, 2004) expects evaluation in stages which are indicated like this:

\begin{tabular}{|l|l|}
\hline Period & Actions \\
\hline 0 & $\begin{array}{l}\text { Any merchant only accepts cash. They set the product price, } p \text { so as to maximize their } \\
\text { profits. }\end{array}$ \\
\hline 1 & The cashless network sets the cardholder fee, $f$ and the industry-specific merchant fee, $m$. \\
\hline 2 & $\begin{array}{l}\text { The merchant decides whether to accept cashless payments or not, and determines the new } \\
\text { price, } q \text {, if it chooses to accept cards. }\end{array}$ \\
\hline 3 & $\begin{array}{l}\text { The consumer decides from which merchant he or she makes purchases, which payment } \\
\text { method he or she uses (if a cardholder), and how much he or she purchases. }\end{array}$ \\
\hline
\end{tabular}

Tab. 1. Merchant's actions regarding to card network period changes. Source: (Hayshi, 2004).

The timing of the game is described in Table 1. We consider a multi-period game and in each period, there are three stages:

- at stage 1 the network sets a merchant fee and card-holder fee,

- at stage 2 the merchants consider outcomes from cost-benefit analysis and decide whether to go cashless or not, and

- at stage 3 the consumers decide from which merchant they make purchases, which payment method they use, and how much they purchase.

Then outcomes of the changes in particular periods can be statistically worked up by Crude Rate $^{2}$ to produce results then we will see ratio of concerned parties who did accept cashless payments and who didn't. Then we can imagine how the electronic payment system within whole society is effective in new user's involvement.

The actual absolute threshold height is different for every merchant and it is based on many facts. Moreover, there are already limitations in each country for maximum amount to be accepted by merchant per one payment (ECCF, 2016, Oltermann, 2016, Beer, Gnan \& Bichler, 2016). These limitations were adopted by member countries and non-directly influence merchants to provide some of the cashless payment methods.

\subsection{Hypothesis verification}

In the subchapter 2.4, three basic hypotheses have been set. Now they are going to be confirmed (or rejected) based on the secondary data collection.

Hypothesis 1: Recently, new statistical reports about contactless payments have been published by LTP Team (2016). As could be seen Czech Republic and Poland are leaders in this domain. There are 0.79 contactless cards per person in the Czech Republic as well as one contactless POS for every nine contactless cards in the same country. Based on such facts, this hypothesis can be confirmed.

\footnotetext{
${ }^{2}$ Crude rate is the ratio of the number of people in which the event of interest happens in a specified time period to the size of the population who may experience this event during the same time period. There are no adjustments made when a crude rate is given.
} 
Hypothesis 2: There some new information about cash deposit and counting by Durden (2016). For example, according to a 2014 study commissioned by PayPal the cost of cash, to small businesses in the UK, is $£ 2.5$ billion per year and about a fortnight in terms of time lost. There are also legal regulations in certain countries (Durden, 2016), which disallow cash to be accepted, to prevent corruption. This hypothesis can be then confirmed.

Hypothesis 3: European Commission (2016c) released in December 2016 Directive on Payment Services, which, among others, significantly reduces interchange fees in the epayments area and introduces conditions for general cashless payments ecosystem. This hypothesis can be then confirmed as well.

\section{Discussion and conclusion}

The cost-benefit relation analysis model of interactions between merchants and customers in the cash and cashless payments environment has been proposed. It is inevitable that recent introduction of new ways to pay revived the market. Even though new electronic payment instruments are sort of cool and very convenient it is a question if the extensive regulation of the interchange fees (mainly in the EU) will not influence (slower) the innovation progress in the area of novel approaches how to pay by using electronic means or gadgets. On top of that some general points for discussion could be:

- Fear of the Big-Brother. As said by Google CEO, people tend to sacrifice their privacy in trade of convenience. And upstanding individuals should not be afraid of anything, should they? Presented scheme can be also used to evaluate other economic problems.

- More and more strict regulations imposed on cash, which slowly makes it illegal (according to many EU representatives, this is one of the ways to fight against terrorism. There is also limitation of maximum EUR 10,000 (proposed on $21^{\text {st }}$ of December 2016) to leave EU to prevent indications of criminal activity (European Commission, 2016b).

- Model presented did not cover time savings and lowers risks. However, it is a matter of fact, lower risks are directly connected with convenience. As already mentioned, Czech Republic and Poland are NFC payment (small amount) leaders - because it is fast, but not safe (there is no PIN needed for payment up to CZK 500 maximum five times per day (CZK 2500 in total). Question for discussion here could be to extend the model with these benefits.

This paper tried to present an advanced general model, on which merchants (and customers) can rely on when they have to decide to accept one (or more) cashless payment methods or to keep cash possession with all related extra costs, including the risk of losing potential customers. In general, every merchant who considers growth and expansion that covers increase of cash flow should think about new payment methods, which strongly correlates with higher amount of customers, raise of orders and increasing absolute amount of "virtual" money turnover.

\section{References}

Beer, Ch., Gnan, E., \& Birchler W. U. (2016). Cash on Trial. Vienna: SUERF.

Chee, Y. F. (2014). MasterCard loses EU court battle over cross-border fees. Reuters USA. Retrieved from: http://www.reuters.com/article/us-mastercard-court-eu-idUSKBNOH60N220140911 
Ching, A., \& Hayashi, F. (2006). Payment Card Rewards Programs and Consumer Payment Choice. Payments System Research, Federal Reserve Bank of Kansas City, Working Paper 06-02. Retrieved from: http://www.kc.frb.org/PUBLICAT/PSR/RWP/Ching Hayashi Paper.pdf

Dove Consulting. (2005). The 2005/2006 Study of Consumer Payment Preferences. Dove Consulting and The American Bankers Association. Retrieved from:

http://www.aba.com/products/surveys/pages/ss cpps 05.aspx

Durden, T. (2016). Cashless Society - Is The War On Cash Set To Benefit Gold? Retrieved from: http://www.zerohedge.com/news/2016-10-23/cashless-society-war-cash-set-benefit-gold

European Commission. (2015). Commission welcomes European Parliament vote to cap interchange fees and improve competition for card-based payments - Press release. Retrieved from: http://europa.eu/rapid/press-release IP-15-4585 en.htm

European Commission. (2016a) Antitrust: Regulation on Interchange Fees - Fact Sheet. Retrieved from: http://europa.eu/rapid/press-release MEMO-16-2162 en.htm

European Commission. (2016b). Directive on Payment Services (PSD). Retrieved from: http://ec.europa.eu/finance/payments/framework/index en.htm

European Commission. (2016c). Cash controls - New proposal. Retrieved from: https://ec.europa.eu/taxation customs/individuals/cash-controls/cash-controls-new-proposal en

ECCF. (2016). Limit for cash payments in EU. Retrieved from: http://www.europeconsommateurs.eu/fileadmin/user upload/euconsommateurs/PDFs/PDF EN/Limit for cash payments in EU.pdf

Evans, D., \& Schmalensee R. (2005). Paying with Plastic: The Digital Revolution in Buying and Borrowing. 2nd ed. Cambridge: MIT Press.

Farrell, J. (2006). Efficiency and Competition between Payment Instruments. Review of Network Economics, 5(1), 26-44. doi: 10.2202/1446-9022.1087

Garcia-Swartz, D. D., Hahn, R. W., \& Layne-Farrar, A. (2004). The Move toward a Cashless Society: A Closer Look at Payment Instrument Economics. AEI-Brookings Joint Center Working Paper No. 04-20. Retrieved from: http://ssrn.com/abstract=641441

Garcia-Swartz, D. D., Hahn, R. W., \& Layne-Farrar, A. (2006). The Move Toward a Cashless Society: Calculating the Costs and Benefits. Review of Network Economics, 5(2), 199-228. doi: $\underline{10.2202 / 1446-9022.1095}$

Hayashi, F. (2006). A puzzle of card payment pricing: why are merchants still accepting card payments? Review of Network Economics, 5(1), 144-174. doi: 10.2202/1446-9022.1093

Hayashi, F., \& Klee E. (2003). Technology Adoption and Consumer Payments: Evidence from Survey Data. Review of Network Economics, 2(2), 175-190. doi: 10.2202/1446-9022.1025

Katz, M. (2001). Reform of Credit Card Schemes in Australia II: Commissioned Report. Retrieved from: http://www.rba.gov.au/payments-and-infrastructure/credit-cards/ii-commissioned-report/

LTP Team. (2016). How the Czech Republic and Poland Are Amongst the Leaders in Contactless Payments. Lets Talk Payments Team. Retrieved from: https://letstalkpayments.com/how-theczech-republic-and-poland-are-amongst-the-leaders-in-contactless-payments/

Oltermann, P. (2016). German plan to impose limit on cash transactions met with fierce resistance. The Guardian. Retrieved from: https:/www.theguardian.com/world/2016/feb/08/german-planprohibit-large-5000-cash-transactions-fierce-resistance

Pražská, B., Otáhalíková H., \& Dostál, F. (2016). Electronic Record-keeping of Cash Sales. Retrieved from: http://www.kemphoogstad.cz/en/dl2?id=31\&lng=en

Rochet, J.-C., \& Tirole J. (2006), Externalities and Regulation in Card Payment Systems. Review of Network Economics, 5(1), 1-14. doi: 10.2202/1446-9022.1085

Rochet, J.-C., \& Tirole. J. (2002). Cooperation among Competitors: Some Economics of Payment Card Associations. RAND Journal of Economics, 33(4), 549-570. 
Rochet, J.-C., \& Tirole, J. (2003). An Economic Analysis of the Determination of Interchange Fees in Payment Card Systems. Review of Network Economics, 2(2), 69-79. doi: 10.2202/1446$\underline{9022.1019}$

Wang, Z. (2006). Market Structure and Credit Card Pricing: What Drives the Interchange? Payments System Research, Federal Reserve Bank of Kansas City, Working Paper 06-04. Retrieved from: http://www.kc.frb.org/PUBLICAT/PSR/RWP/Wang-WP-06-04.pdf

Weiner, S. E., \& Wright, J. (2006). Interchange Fees in Various Countries: Developments and Determinants. Payments System Research Department, Federal Reserve Bank of Kansas City, Working Paper 05-01. Retrieved from:

https://www.newyorkfed.org/medialibrary/media/research/conference/2005/antitrust/WeinerWrigh t.pdf

Wolman, D. (2013). The End of Money: Counterfeiters, Preachers, Techies, Dreamers - and the Coming Cashless Society. Philadelphia: Da Capo Press.

Zhou, CH., \& Zhang, CH. (2006). Provide a trusted platform for mobile electronic payment. SANS Institute. Retrieved from: https://www.sans.org/reading-room/whitepapers/ecommerce/trustedsmart-phone-applications-electronic-payment-1656 